\title{
Multi-disciplinary approach in engineering education: learning with additive manufacturing and reverse engineering
}

\begin{abstract}
Purpose

The paper reports on an inter-disciplinary, cooperative-learning project in a second-year course within the "Enzo Ferrari" Master of Science Degree in Mechanical Engineering. The work aims to raise awareness of the educational impact of additive manufacturing and reverse engineering.

Design/methodology/approach

Students are asked to develop, concurrently, the design and the manufacturing solution for an eyetracker head mount. A digital head model is reverse engineered from an anatomical mannequin and used as an ergonomic mock-up. The project includes prototype testing and cost analysis. The device is produced using additive manufacturing techniques for hands-on evaluation by the students.
\end{abstract}

\section{Findings}

Results of the presented case study substantiate the authors' belief in the tremendous potential of inter-disciplinary project-based learning, relying on innovative technologies to encourage collaboration, motivation and dynamism.

\section{Originality/value}

The paper confirms a spreading conviction that the soon-to-be engineers will need new practiceoriented capabilities, to cope with new competitive scenarios. Engineering education must adapt to the social, rather than industrial, revolution that is being brought about by additive fabrication.

Keywords: Additive Manufacturing, Fused Deposition Modelling, Education, cooperative-learning, Reverse Engineering

\section{Introduction}

Teaching methods in engineering education are drawing wide attention. In the US, the Accreditation Board for Engineering and Technology expressed the following recommendations (Felder et al., 2000).

- Teach more about "real-world" engineering design and operations.

- Cover more material in frontier areas of engineering.

- Offer more and better instruction in both oral and written communication skills and teamwork skills.

- Provide training in critical and creative thinking skills and problem-solving methods.

In the authors' opinion, the same needs apply to European engineering education. In the field of engineering, virtual learning environments can promote the development of a problem solving approach (Gómez and Rodríguez-Marciel, 2012), but some of the "real-world" difficulties only arise in physical hands-on experiences. The capability of making something work can hardly be attained on a virtual basis. Educational methods should foster actionable learning (Mohanty \& Deshmukh, 1998), especially in technology courses. Sometimes the core of the didactic action is problem solving, but the activities are limited to a virtual context, which lacks the complexity of a real manufacturing environment. As a matter of fact engineers, as they need to act as technological 
problem solvers, are supposed to respond to calls from society, much as a consultant responds to clients (Downey, 2005).

Simulation does not always help students find quick solutions to many practical, technical and mechanical problems, nor it teaches how to contact a vendor for a quote request, to negotiate a price or to take "make or buy" decisions about a component. All of these capabilities are best achieved in project-based learning (Mills \& Treagust, 2003). The tasks of designing, fabricating and testing a component for form, fit and function, contribute to expose students to the real-world design and manufacturing cycle (Kroll and Artzi, 2011).

The advent of additive manufacturing and reverse engineering provides a means to reduce the cost and to shorten the time associated with obtaining conceptual prototypes and functional models. These technologies are becoming established in industry, as well as they are now reaching mass distribution with the advent of entry-level models. Yet, in many countries, their use in academia is still in the early stages of development (Kianian et al., 2015). Even if the numbers are growing, much potential is still unexplored (Beyer, 2014; Bourell et al., 2014). In Universities, additive manufacturing equipment is often handled as part of research efforts, or for the purpose of training students on the specific operation of rapid prototyping machines. In more interesting examples, additive fabrication is used to enhance the education experience by supporting other didactic objectives (Stamper and Dekker, 2000; Flinn, 2012). Similarly, in the review by Snyder et al. (2014), the impact of layer-manufactured models in education is affirmed, but only from the perspective of how physical models can foster learning of non-engineering disciplines. AM holds the potential to improve engineering education (Campbell et al., 2012), in that it can engage students in a teaching factory setting (Huang et al., 2015, Wong et al., 2014) and it allows action learning (Geraedts et al., 2012). While Huang and Leu (2014) report the readiness of US educational institutions to include AM in the curricula, in Europe the adjustment is slower. In Italy, which this case study refers to, only two Universities are recognized for their expertise in AM (Wohlers, 2014).In 2014 NMC Report, the time-to-adoption horizon of 3D printing is estimated to be two to three years (Johnson et al., 2014). Gao et al. (2015) discuss the urgency of educating an AM engineering workforce, capable of overcoming the barrier to adoption due to unfamiliarity with these technologies. The same authors report on dedicated AM courses at the undergraduate and graduate levels, but they consider the scenario still far from matching the recent interest in, and suggested national importance of, the technology.

Project work can involve inter-disciplinary approaches, which inspire creative breakthroughs and are instrumental to the process of learning to learn (Marques, 2008). The emergence of novel academic fields is often the result of inter-disciplinary cooperation.

For the concepts of intra-disciplinarity, multi-disciplinarity and inter-disciplinarity, the authors embrace Van Dusseldorp's definitions (1992). Inter-disciplinarity implies a high level of disciplinary interaction that can be categorized into six criteria:

1) Common object;

2) Simultaneity;

3) Involvement of specialists of different disciplines;

4) Work in close collaboration;

5) Constant exchange of information;

6) Sharing of the same goal to achieve an integrated analysis.

An inter-disciplinary approach can contribute most effectively to counterbalance specialization, by widening the horizons and providing a richer and more global awareness of the fields of application of engineering methods and techniques.

The present paper reports on an inter-disciplinary, cooperative-learning project, developed by the students attending the "Computer Aided Production (CAP)" course, within the Master of Science Degree in Mechanical Engineering at the Department of Engineering "Enzo Ferrari", in Modena 
(Italy). Students are asked to develop, concurrently, the design and the manufacturing solution for an eye-tracker head mount. The device must meet requirements as to ergonomics, ease of manufacture and economy, to ensure the largest possible number of end users. The head mount is produced, tested and evaluated by the students themselves. They are also requested to provide a cost analysis, as a function of lot size and production volume.

The project target is to lead students to the $6^{\text {th }}$ level of Bloom's cognitive domain: evaluation, meant as choosing among alternatives and justifying the choice, optimizing processes, making judgments about the environmental impact of engineering decisions, resolving ethical dilemmas (Bloom and Krathwohl, 1984).

\section{Contextualization of the educational project}

Each year, the course attracts approximately 50-55 students. Main specifications about topics and organization are given below.

\section{Learning goals}

The course aims at the acquisition of knowledge and operational capabilities regarding:

1. Industrial organization, company structure and product development;

2. Computer-Aided-design (CAD), -engineering (CAE), -manufacturing (CAM), -process planning (CAPP);

3. Additive manufacturing;

4. Reverse engineening;

5. Advanced manufacturing technologies.

\section{Course organization}

The course is comprised of: lectures, practice in the use of CAD-CAM software tools (computer lab), plenary laboratory sessions dedicated to the use of machines, tutorials, group work. Groups are formed by the instructor.

\section{$\underline{\text { Project topic }}$}

Eye-tracking devices for computer interaction are a fascinating application of technology: revolutionary for users with reduced mobility, but groundbreaking in any task requiring the use of hands (Jacob, 1991). Video eye trackers detect a user's gaze direction by observing the eye with a high-resolution camera and measuring the positions of the pupil: the device works as a mouse controlled by gaze direction (Morimoto \& Mimica, 2005).

When targeted to the general public and common computer interfaces, an eye tracker should (Duchowski, 2007):

- Ensure accuracy of minutes of arc;

- Guarantee reliability, i.e., have constant, repetitive behaviour and real-time response;

- Be robust, i.e, should work under different conditions, such as light fluctuations;

- Be non-intrusive, i.e., cause no harm or discomfort, be compact;

- Allow for free head motion;

- Require easy calibration and instant setup.

In this project, eye-tracking technology is developed by the ELASTYC Laboratory (Dept. of Biological Sciences - University of Modena and Reggio Emilia), which gives the necessary knowledge support as to the electronics and software, and sets the specifications of the head mount. The mount should be flexible enough to account for the variability of relevant anatomical and physiological characteristics among different individuals. The mini-camera has a focal length of $8 \mathrm{~mm}$ and a field of vision of $40^{\circ}$. It must be oriented toward the dominant eye, about $70 \mathrm{~mm}$ far and at the edge of the field of view, so that the eye is captured under weak perspective. The output PAL 
signal, with 380 horizontal lines resolution, is sent to a low-cost video acquisition device, which communicates with the PC via USB 2.0. The video signal can be digitalized with a pixel resolution up to $720 \times 576$. A good image contrast is obtained using one or two IR LEDs, with peak emission wavelength of $890 \mathrm{~nm}$, positioned in proximity of the camera, but with an off-axis orientation to produce the well-known dark-pupil effect. This setup allows an easy pupil-image identification in every acquired video frame, because the pupil is seen darker than the remaining frame. A further specification comes from the eventuality that the superior eyelid or the eyelashes cause pupil image obstruction. The software can partially overcome the loss of information, but in most cases this annoying situation can be avoided adopting the simple and useful solution of positioning the camera below the eye level.

A draft of the eye-tracker layout is shown in Figure 1.

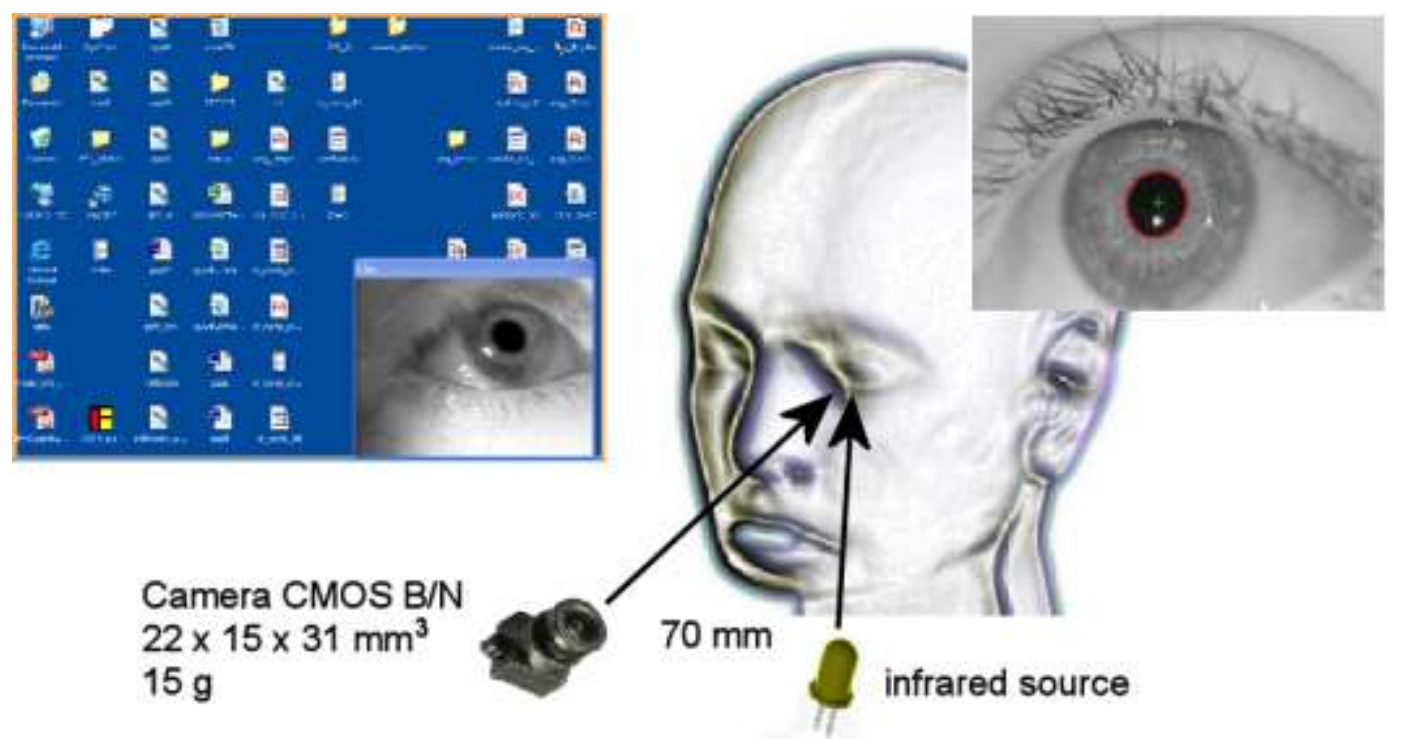

Figure 1. Camera specifications and draft of system layout.

\section{The project}

The project is aimed at the concurrent development of the design and of the manufacturing solution for aneye-tracker head mount. The product must meet requirements as to ergonomics, ease of manufacture and economy, envisioning the largest possible market.

Students are asked to design the head mount by using a digital head model, obtained by reverse engineering a mannequin for anatomical studies. In this phase, summarized in Figure 2, students work with the support of the teaching staff. Students take part to the reverse engineering activities, but at the end the same digital model of the head (in the STL format) is given to all groups. Electrooptical and signal processing knowledge is not part of the cultural background of students enrolled in the Mechanical Engineering MS program. Therefore, in accordance with Felder and Brent (1996), time is spent during the first lesson to introduce students to these topics, as well as to eyetracking technologies. Background information prepares students and simulates an engineering working environment, so it increases interest and commitment in the project. Under this perspective, that the subject of the project has a high social value fosters students' motivation. 


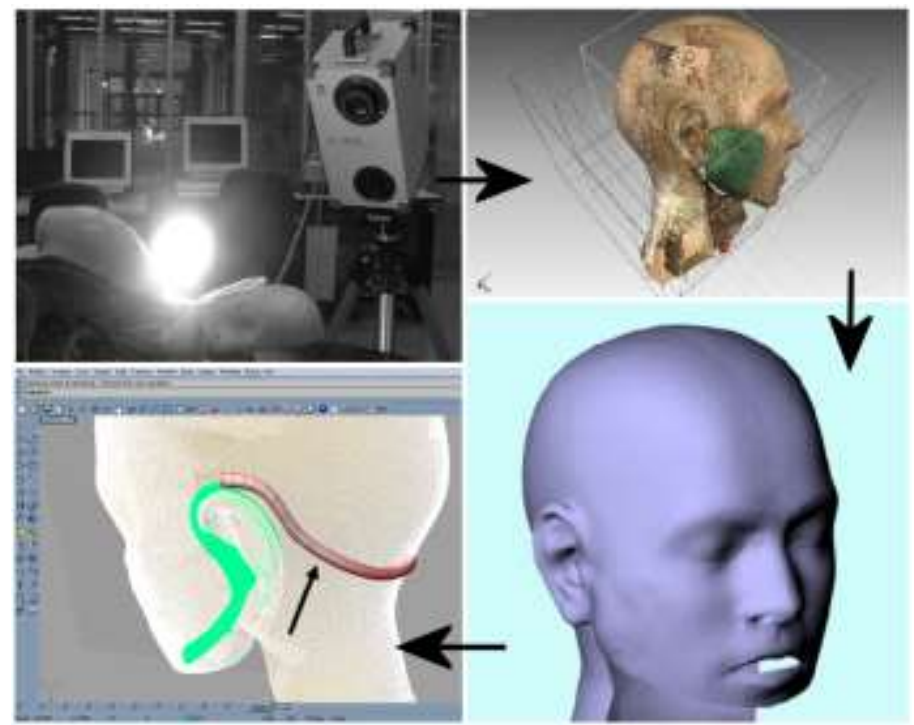

Figure 2. Reverse engineering of an anatomical mannequin to obtain a digital head model.

Students work in cooperative learning groups. Activities have to be scheduled in a timetable and assigned to one or more group members. Tasks and deadlines are decided within the group and have to be specified in the project documentation, through the use of Perth and Gantt charts. Cooperative learning (CL) is an instructional approach in which students work in teams on a learning task, structured to have specific features (Johnson et al., 1998). Table 1 details how general aspects of cooperative learning apply to the present project.

Table 1: How cooperative learning is applied in the project.

Positive independence

Individual accountability

Face-to-face promotive interaction

\section{Appropriate use of interpersonal and teamwork skills.}

Regular self-assessment of team functioning
The group shares a common challenging goal: the creative product- and process development of an eye-tracker head mount.
After a preliminary investigation on the state of the art, the group proceeds to the selection of the design solution that must be shared by the whole group

After a period of training in the safe operation of equipment, students have selfaccess to the machines. A team-leader coordinates the activities and is in charge of access requests and documentation delivery.

Teams are periodically asked to evaluate the project's progress.

\section{Results}

Figure 3 shows some of the designs proposed by the students. An interesting result is that most groups choose, on their own initiative, a knowledge-base organization. Key markers that distinguish job organization in the industrial-, compared to the knowledge-age, are summarized in Table 2 (Reigeluth, 1999).

Students themselves run an AM machine (Dimension Elite, Stratasys Inc., USA) in the lab, in order to acquire operational skills as file opening, machine maintenance, launch of construction, support removal. Yet, the whole set of prototypes designed during the project is produced at Politecnico di Torino, by using the same machine. This project structure lets the students experience outsourcing: 
they send the digital model and receive the physical one, so they need to face problems related to data transfer (size file and format, information exchange, ..) and logistics (order schedule, lead time). In this sense, production of prototypes contributes to the acquisition of organizational and relational capabilities (Sheppard et al., 2003). Previous studies point out AM machine scheduling as a significant issue in similar projects (Marchese et al., 1999).

Students access the course with a solid modeling background, however, during the hours of CADCAM laboratory, they learn to use an industrial CAD/CAM software (VISI, Vero Software Limited). This is enough to guarantee students' operational autonomy.

Figure 4 shows some of the prototypes. In the final step, students test the assembled device and evaluate ergonomic performances, such as fit and comfort, but also aesthetics and ease of assembly. One of the head mounts is chosen for a functional test, to be performed with the eye-tracking system. The students themselves select the "best design", which is produced by selective laser sintering using Aluminium-filled Polyamide (Figure 5). The material/process selection comes from previous research experiences of the teaching staff, who transfer their scientific knowledge to the students (Berti et al., 2010; Bassoli et al., 2012). The final device is well appreciated by the colleagues who developed the eye-tracking system and is taken into account for possible industrialization. The cost analysis for the head-mount, shown in Table 3, suggests promising benefits of the solution over similar products that are available on the market.

Table 2: Key markers distinguishing industrial-age and knowledge-age.

\begin{tabular}{ll}
\hline Standardization & Customization \\
\hline Bureaucratic organization & Team-based organization \\
Centralized control & Autonomy with accountability \\
Adverse relationships & Cooperative relationships \\
Autocratic decision making & Shared decision making \\
Compliance & Initiative \\
Conformity & Diversity \\
One-way communications & Networking \\
Compartmentalization & Holism \\
Parts-oriented & Process-oriented \\
Planned obsolescence & Total quality \\
Manager kingdom & Customer kingdom \\
\hline
\end{tabular}

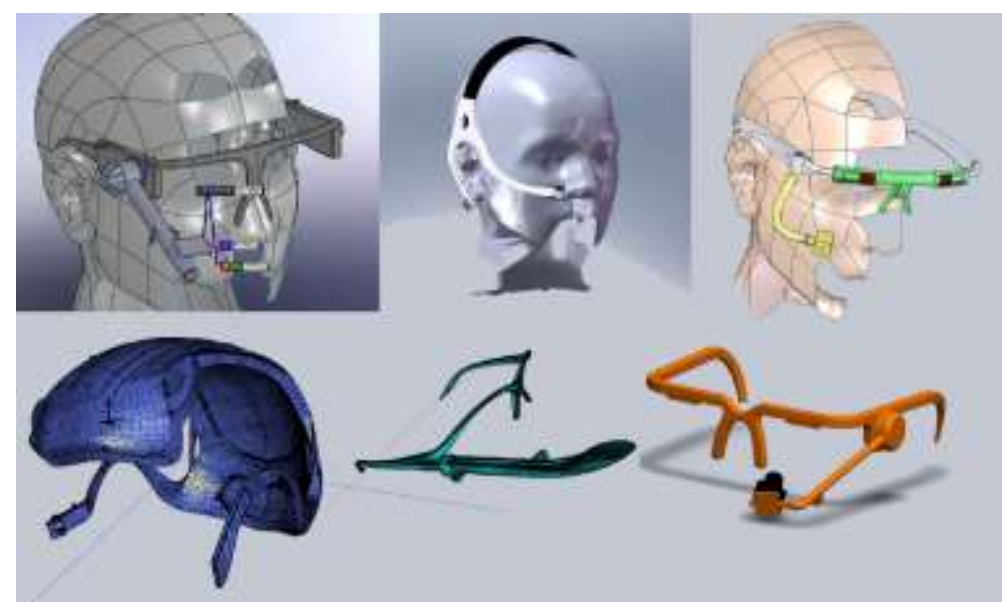

Figure 3. Examples of designs proposed by the students. 


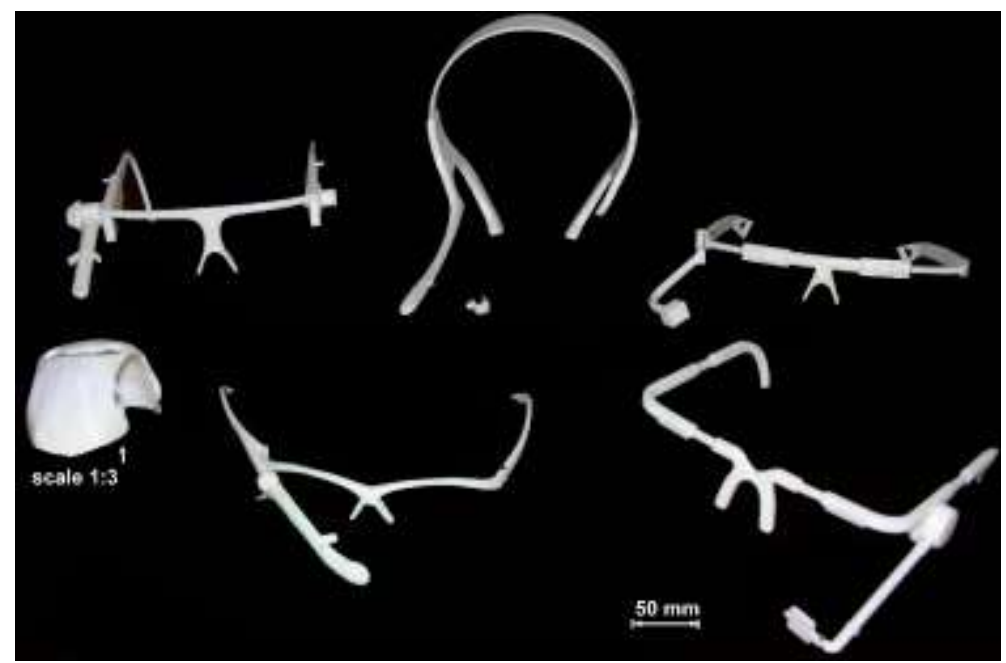

Figure 4. Some of the prototypes produced

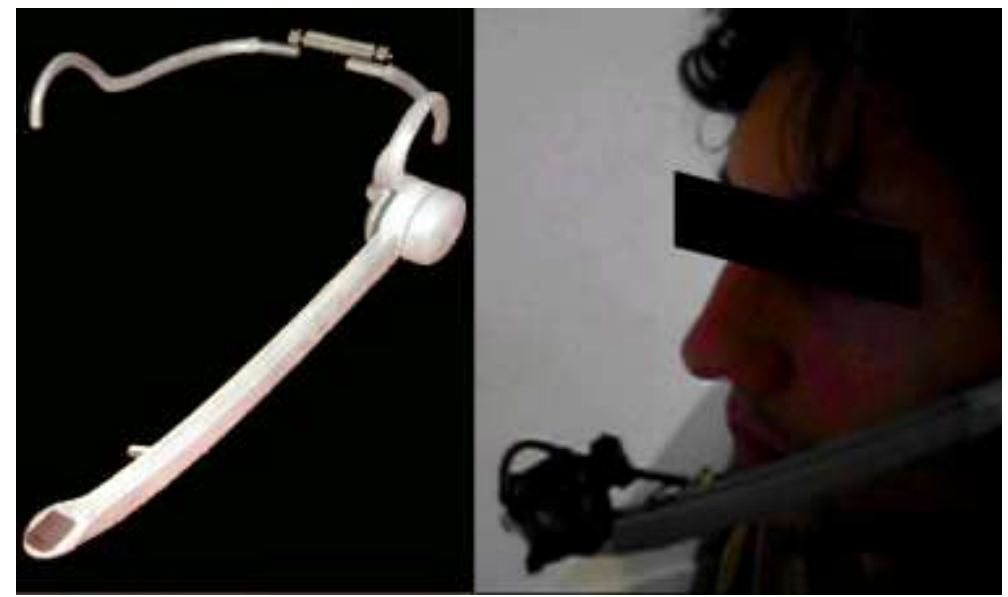

Figure 5. Functional test of the selected "best design".

Table 3. Cost analysis for the selected prototype

\begin{tabular}{lr}
\hline components & $\boldsymbol{\epsilon}$ \\
\hline Mini-camera and wires & 40 \\
Infrared led and wires & 0,50 \\
Data acquisition board & 50 \\
Prototype of the head mount & 200 \\
Other components & 2,50 \\
Total & $\mathbf{2 9 3}$ \\
\hline
\end{tabular}

\section{Conclusions}

The projects results in high assessment compared to previous experiences in the CAP course. The projects are evaluated on the following aspects:

- Quality of goal analysis (commercial target, market, social impact, state of art);

- Quality of the solution analysis (reasons for the choice, cost, supply chain, complexity);

- Quality of the solution selection (criteria, keywords);

- Quality of prototype (how far is the prototype from the designed object?);

- Team organization and efficiency (Are the Perth and Gantt diagrams respected? Is the report clear and detailed?)

More than $90 \%$ of the students achieved marks higher than 27 , where the maximum is 30 . 
Results of the presented case study substantiate the authors' belief in the potential of such dynamic initiatives in engineering education. Inter-disciplinary project-based learning, relying on innovative technologies, proved effective in encouraging collaboration, motivation and acquisition of capabilities. The integration of additive manufacturing on one side, as a tool for making physical what students imagine and design digitally, and of reverse engineering on the other, which instead turns digital something that is physically available, has a groundbreaking impact in technical teaching. The described loop shapes students' thinking of new products.

The paper confirms a spreading conviction that the soon-to-be engineers will need new practiceoriented capabilities, to cope with new competitive scenarios. Engineering education must adapt to the social, rather than industrial, revolution that is being brought about by additive fabrication.

\section{References}

Bassoli, E., Gatto, A. and Iuliano, L. (2012), "Joining mechanisms and mechanical properties of PA composites obtained by selective laser sintering”, Rapid Prototyping Journal, Vol. 18 No. 2, pp. 100-108.

Berti, G., D'Angelo, L., Gatto, A. and Iuliano, L. (2010), "Mechanical characterisation of PAA12O3 composites obtained by selective laser sintering", Rapid Prototyping Journal, Vol. 16 No. 2, pp. 124-129.

Beyer, C. (2014), "Strategic Implications of Current Trends in Additive Manufacturing", Journal of Manufacturing Science and Engineering, Vol. 136, pp. 064701-1

Bloom, B.S. and Krathwohl D.R. (1984), Taxonomy of Educational Objectives: A Classification of Educational Objectives. Handbook 1: Cognitive Domain, Longman, New York.

Bourell, D. L., Rosen, D. W., \& Leu, M. C. (2014). The Roadmap for Additive Manufacturing and Its Impact. 3D Printing and Additive Manufacturing, Vol. 1 No. 1, pp. 6-9.

Campbell, I., Bourell, D., \& Gibson, I. (2012). Additive manufacturing: rapid prototyping comes of age. Rapid Prototyping Journal, 18(4), 255-258.

Downey, G. (2005), "ARE ENGINEERS LOSING CONTROL OF TECHNOLOGY? From 'Problem Solving' to 'Problem Definition and Solution' in Engineering Education", Chemical Engineering Research and Design, Vol. 83 No.6, pp.: 583-595.

Duchowski, A. (2007). Eye tracking methodology: Theory and practice (Vol. 373). Springer Science \& Business Media.

Felder, R.M. and Brent, R. (1996), "Navigating The Bumpy Road to Student-Centered Instruction" College Teaching, Vol. 44 No. 2, pp. 43-47.

Felder, R.M., Woods, D. R., Stice, J. E., and Rugarcia, A. (2000), "The Future Of Engineering Education II. Teaching Methods That Work", Chemical Engineering Education, Vol. 34 No. 1, pp. 26-39.

Flynn, E. P. (2012, March). Design to manufacture-Integrating STEM principles for advanced manufacturing education. In Integrated STEM Education Conference (ISEC), 2012 IEEE 2nd (pp. 1-4). IEEE.

Gao, W., Zhang, Y., Ramanujan, D., Ramani, K., Chen, Y., Williams, C. B., ... \& Zavattieri, P. D. (2015). The status, challenges, and future of additive manufacturing in engineering. Computer-Aided Design.

Geraedts, J., Doubrovski, E., Verlinden, J., \& Stellingwerff, M. (2012). Three views on additive manufacturing: business, research and education. In Ninth Int. Symp. Tools Methods Compet. Eng., I. Horváth, A. Albers, M. Behrendt, and Z. Rusák, Eds (pp. 1-15).

Gómez, E. and Rodríguez-Marciel, C. (2012), "PGDnet: a new problem-solving virtual learning environment", British Journal of Educational Technology, Vol. 43 No. 4, pp. 576-591. 
Huang, Y., \& Leu, M. C. (2014). Frontiers of Additive Manufacturing Research and Education.

Huang, Y., Leu, M. C., Mazumder, J., \& Donmez, A. (2015). Additive Manufacturing: Current State, Future Potential, Gaps and Needs, and Recommendations. Journal of Manufacturing Science and Engineering, Vol. 137 No. 1, pp. 014001-10.

Jacob, R. J. (1991). The use of eye movements in human-computer interaction techniques: what you look at is what you get. ACM Transactions on Information Systems (TOIS), 9(2), 152-169.

Kianian, B., Tavassoli, S., \& Larsson, T. C. (2015). The Role of Additive Manufacturing Technology in Job Creation: An Exploratory Case Study of Suppliers of Additive Manufacturing in Sweden. Procedia CIRP, 26, 93-98.

Kroll, E. and Artzi, D. (2011), "Enhancing aerospace engineering students' learning with 3D printing wind-tunnel models", Rapid Prototyping Journal, Vol. 17 No. 5, pp. 393-402.

Johnson, D.W., Johnson, R.T., and Smith, K.A. (1998), Active Learning: Cooperation in the College Classroom, 2nd ed., MN: Interaction Book Co., Edina.

Johnson, L., Becker, S., Estrada, V., \& Freeman, A. (2014). Horizon Report: 2014 Higher Education.

Marchese, A., Schmalzel, J., Mandayam, S., and Chandrupatla, T. (1999), “A Venture Capital Fund to Encourage Rapid Product Development with Multidisciplinary Teams in the Junior Engineering Clinic", in Proceedings of the 1999 ASEE Annual Conference, Charlotte, North Carolina, June 20-23 1999.

Marques J. M. M. C. (2008), "Inter and multidisciplinarity in engineering education”, International Journal of Mechanics and Materials in Design, Vol. 4 No. 2, pp. 229-237.

Mills, J. E., \& Treagust, D. F. (2003). Engineering education-Is problem-based or project-based learning the answer?. Australasian Journal of Engineering Education, Vol. 3 No. 2.

Mohanty, R.P., Deshmukh, S.G. (1998), "Advanced manufacturing technology selection: A strategic model for learning and evaluation”, International Journal of Production Economics, Vol. 55 No. 3, pp. 295-307

Morimoto, C. H., \& Mimica, M. R. (2005). Eye gaze tracking techniques for interactive applications. Computer Vision and Image Understanding, Vol. 98 No.1, pp. 4-24.

Pahl, G., Badke-Schaub, P. and Frankenberger, E. (1999), "Rèsumè of 12 years interdisciplinary empirical studies of engineering design in Germany", Design Studies, Vol. 20 No.5, pp. 481-494.

Reigeluth, C.M. (1999), “What Is Instructional-Design Theory and How Is It Changing?”, in Reigeluth, C.M. (Ed.) Instructional-Design Theories and Models, Volume II: A New Paradigm of Instructional Theory, Lawrence Erlbaum Assoc., Mahwah, NJ, pp. 5-30.

Sheppard, K., Dominick, P. and Aronson, Z. (2003), "Preparing Engineering Students for the New Business Paradigm of International Teamwork and Global Orientation" in proceeding of ECI Conference on Enhancement of the Global Perspective for Engineering Students by Providing an International Experience, Tomar, Portugal.

Snyder, T., Weislogel, M., Moeck, P., Stone-Sundberg, J., Birkes, D., Hoffert, M. P., ... \& Graft, J. (2014). 3D Printing and Additive Manufacturing: 3D Systems Technology Overview and New Applications in Manufacturing, Engineering, Science, and Education. In NIP \& Digital Fabrication Conference (Vol. 2014, No. 1, pp. 146-151). Society for Imaging Science and Technology.

Stamper, R. E. and Dekker, D. L. (2000), "Utilizing rapid prototyping to enhance undergraduate engineering education" Frontiers in Education Conference, FIE 2000, 30th Annual , Vol.2, pp.F3C/1,F3C/4 
Van Dusseldorp, D. (1992), "Integrated rural development and interdisciplinary research: a link often missing", Bakker, J.I. (Ed.) Integrated Rural Development Review, GuelphWageningen Rural Development Network, Guelph, Canada, pp. 35-58.

Wohlers, T. (2014) Wohlers report 2014: 3D Printing and Additive Manufacturing State of the Industry. Annual Worldwide Progress Report. Fort Collins, CO: Wohlers Associates.

Wong, D. S., Zaw, H. M., \& Tao, Z. J. (2014). Additive manufacturing teaching factory: driving applied learning to industry solutions: This paper reviews the past and current status of AM technology at Nanyang Polytechnic in Singapore. Virtual and Physical Prototyping, Vol. 9 No. 4, pp. 205-212. 